\title{
«BARRIO DE INDIOS»: ARQUEOLOGÍA DE UNA PARROQUIA URBANA PERIFÉRICA EN LA CIUDAD COLONIAL DE RIOBAMBA, ECUADOR
}

\author{
Ross W. Jamieson ${ }^{a}$
}

\begin{abstract}
Resumen
La excavación de basurales de dos casas de barrios periféricos de la ciudad colonial de Riobamba, en la Audiencia de Quito (hoy Ecuador), ha incluido el análisis de restos botánicos y de fauna con el fin de lograr un mejor entendimiento de las relaciones existentes entre raza, clase social y cultura material en una ciudad andina del siglo XVIII. A pesar de que las autoridades locales del siglo XVI intentaron mantener barrios exclusivos para la gente indigena, para el siglo XVIII, estos mismos barrios se transformaron en lugares racialmente mestizos. Pese a una naturaleza hibrida de los materiales culturales en estos contextos, la pobreza, un estatus de artesanos y la clasificación racial de «indios" fueron factores determinantes en la vida de quienes poblaron la parroquia San Blas en siglo XVIII. Gran parte de la arqueología histórica se enfoca al nivel de unidades domésticas en la escala de análisis y, aun para entornos urbanos, es importante también considerar a la parroquia, o vecindario, como una importante unidad de análisis.
\end{abstract}

Palabras clave: Ecuador, arqueología histórica, vida doméstica, identidad, artesanos

\section{Abstract \\ «BARRIO DE INDIOS»: ARCHAEOLOGY OF AN URBAN PERIPHERAL PARISH IN THE COLONIAL CITY OF RIOBAMBA, ECUADOR}

Excavation of middens from two households in a peripheral parish of the colonial city of Riobamba, in the Audiencia of Quito (today Ecuador), has included analysis of faunal and botanical remains, in order to better understand the relationship between race, social class, and material culture in the 18th century Andean city. Although city officials of the 16 th century attempted to maintain separate neighborhoods for indigenous people, by the 18th century such neighborhoods had become racially mixed. Despite the hybrid nature of the material remains in such households, poverty, status as artisans, and racial classification as indios were still significant factors in the lives of those who lived in the San Blas parish in the 18th century. Much historical archaeology focuses on the level of households as a scale of analysis, and yet for urban environments, it is important to also consider the parish, or neighborhood, as an important unit of analysis.

Keywords: Ecuador, historical archaeology, identity, domestic life, artisans

\footnotetext{
${ }^{a}$ Departamento de Arqueología, Simon Fraser University, Burnaby Correo electrónico: rossjami@sfu.ca
} 


\section{Introducción}

El 4 de febrero de 1797 la ciudad de Riobamba en Ecuador fue destruida luego de uno de los terremotos más devastadores históricamente registrados en la región, que se cree pudo haber llegado a ser de magnitud 8,3 en la escala de Ritcher. Como consecuencia, la ciudad fue trasladada y completamente reconstruida en un nuevo lugar, 17 kilómetros al noreste de la antigua ciudad (Terán Najas [ed.] 2000; Egred 2004). Los remanentes de la ciudad colonial están ahora debajo y en los alrededores del pueblo de comerciantes llamado Sicalpa/Cajabamba.

Luego del terremoto, la realización de un mapa de la nueva ciudad fue convenida detallando la locación exacta de todas las calles y propiedades en la Riobamba del siglo XVIII. Basados en una copia del mapa original de 1828 (Fig. 1; Nolasco Yépez 1828), hemos identificado la parroquia de San Blas en la periferia suroeste de la ciudad. En una calle del sector norte de la parroquia, por donde aquellos que entraban desde el centro de la ciudad debieron haber pasado, el cartógrafo ha escrito "Barrio de Indios», con lo cual crea una clara línea racial entre el centro de la ciudad de Riobamba y los habitantes de San Blas, definidos por el cartógrafo como gente indígena. Desde 2003, el Proyecto Arqueología Histórica de Sicalpa ha excavado contextos urbanos de la Riobamba colonial como un esfuerzo por visualizar varios aspectos de la cotidianidad en los Andes coloniales (Jamieson 2004; St. Denis 2008; Michaels 2009; Balanzátegui 2012). Un aspecto de este proyecto ha sido la excavación de dos basurales domésticos en el vecindario colonial de San Blas, lo que nos confronta con preguntas acerca de los conceptos sobre identidad indígena en los barrios urbanos coloniales de los Andes.

Las políticas de identidad se hallan en el punto central de la administración en cualquier ámbito colonial y la colonización española de la América Andina no fue la excepción. Los arqueólogos históricos útilmente separan los conceptos de raza, cultura y etnicidad como definiciones concretas y monolíticas de pertenencia al grupo. El concepto posmoderno de «identidad» puede ser útil visto como una categoría multivalente, definido por grupos de personas relacionadas con otras, altamente contextualizado y situacional (Meskell 2002; Orser 2004; Voss 2008; Silliman 2009). Las personas, tal vez, proyecten varias identidades a través de sus vidas o, incluso, en un mismo día dependiendo de las relaciones con otros. La identidad no es, sin embargo, una competencia exclusiva de los individuos para definirse a sí mismos. La agencia individual existe, pero en relación con estructuras macro en la sociedad. Uno de los aspectos más importantes de la formación de identidad en situaciones coloniales es la relación entre el poder del Estado y los grupos colonizados. La relación entre el poder de los Estados coloniales y las decisiones individuales sobre la formación y el mantenimiento de la identidad se crean en varias escalas espaciales de los escenarios coloniales.

«Identidad» ha sido un concepto clave para investigaciones arqueológicas en épocas recientes. Aun para arqueólogos históricos los límites entre conceptos de raza, identidad y clase social no son fáciles de definir, a pesar de la aparente separación habitual de estos conceptos en las mentes de los administradores coloniales (Silliman 2006; Voss 2008). En el sistema colonial, había un claro interés político en las ideas de raza y, en los Andes, esto funcionaba como una política de la identidad urbana centrada en conceptos raciales de identidad. Además, estos factores de raza están incluso íntimamente asociados a ideas sobre clase social y economía (Cope 1994). ¿Existieron ideas separadas sobre raza y clase en las mentes de los colonizadores y colonizados en los Andes de los siglos XVII y XVIII tan fácilmente separadas como lo están en nuestras mentes occidentales? Los historiadores de este período han argumentado eficazmente que la obsesión por el control de la raza en la gobernanza de las áreas urbanas poco a poco se transformó en una discusión sobre el control de las clases sociales, o plebeyos, y los barrios urbanos (Stern 1987; Fisher et al. [eds.] 1990; Moreno Yánez 1995 [1976]; Walker 1999). Como arqueólogo, mi interés es demostrar cómo la cultura material y las relaciones espaciales hablan acerca de estas relaciones cambiantes.

Los restos arqueológicos de basurales en contextos domésticos urbanos coloniales están dominados por utensilios de mesa, ítems de comida y materiales de cocina desechados en los patios 


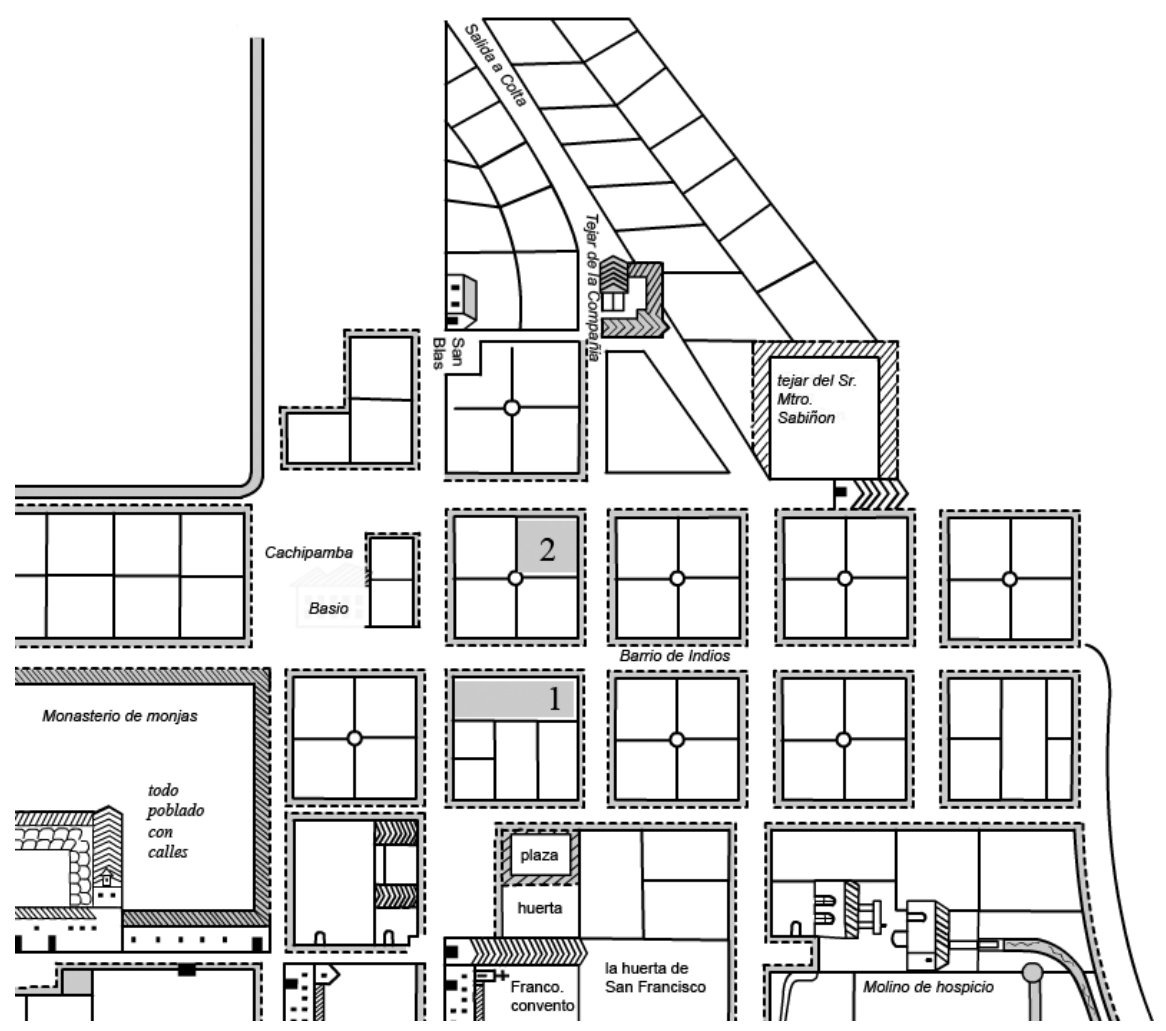

Figura 1. Transcripción de una parte de Nolasco Yépez (1828) mapa de Riobamba antes del terremoto de 1797, que muestra la parroquia de San Blas. El norte está hacia abajo del mapa (como en el original) (Dibujo por R. Jamieson).

traseros. Este tipo de cultura material tiene una relación compleja con la identidad de las personas que vivían en barrios específicos (Schávelzon 2000; Voss 2008; Londońo 2011). Para el análisis de las señales de identidad en barrios urbanos, la categoría de los datos que incorporamos, ya se trate de fauna, restos botánicos o la cultura material de los hogares, nos brinda una gran variedad de resultados en relación con los orígenes de los temas que se discuten y las maneras en que estos se incorporaron en el uso diario en los hogares. Estos estudios arqueológicos, a su vez, hacen frente a datos muy diferentes de los inventarios de los hogares, los diseños urbanos y arquitectónicos, y las descripciones que son el forraje de los historiadores de la identidad urbana en las colonias españolas.

Situaciones en las que las relaciones espaciales son obligadas entre los grupos sociales son útiles para los arqueólogos que estudian identidad en contextos coloniales. En entornos coloniales urbanos, la identidad puede ser explorada a la escala de los barrios o parroquias. Los individuos en las ciudades andinas coloniales se identificaban racialmente, a lo largo de líneas de clases sociales, y a través de ataduras culturales o étnicas, así como a través de ideas sobre género y edad. Estas categorías se intersecaban, sin embargo, en debates acerca de planificaciones urbanas y gobernabilidad en las ciudades coloniales andinas, en las cuales los barrios fueron identificados con "tipos» particulares de gente, tipos que cruzaban los límites entre ideas de etnicidad, raza, case social, ocupación y religión. El control y la administración por parte del gobierno y las autoridades eclesiásticas estuvieron basados en ideas estereotipadas sobre lo que hacía funcional o disfuncional a los barrios, partiendo de conceptos de conversión religiosa y proselitismo, control gubernamental sobre si la gente de razas particulares debería vivir en determinados barrios, y temas alrededor del descontento y la rebelión de alguna etnia específica, racial o grupos ocupacionales organizados a lo largo de las líneas de los barrios. 


\section{La ciudad colonial como disyuntora}

La ciudad de Riobamba está ubicada en el altiplano del Ecuador, un país cuyas fronteras abarcan gran parte de la Audiencia de Quito del período colonial (Fig. 2). Los conquistadores bajo el mando de Sebastián de Benalcázar ocuparon esta porción norte del Imperio inca en 1534 y se desplazaron hacia el norte de Perú a raíz del derrocamiento de Francisco Pizarro por parte de la administración imperial inca (Montes de Oca 1983; Parry y Keith 1984: 442). Luego de la conquista, una serie de ciudades fueron fundadas a lo largo del sistema vial principal inca, contexto en el cual Riobamba se transformó en el centro de este territorio. Riobamba se fundó sobre una ya existente estación de paso inca y su plaza central — se presume que es la misma plaza que forma el núcleo de la ciudad colonial de Riobamba - es la plaza principal de Sicalpa hoy (Oviedo y Valdés 1959 [1535]: tomo V, 112; Terán Najas 2000: 17). A partir del siglo XVI, Riobamba se convirtió en un importante centro secundario en la Audiencia de Quito, estratégicamente situada en la principal ruta nortesur, en el punto en donde la vía desde el principal puerto colonial del pacífico, Guayaquil, llegaba desde la costa. Desde mediados del siglo XVI hasta el final del siglo XVIII, Riobamba mantuvo su condición de centro de operaciones en la administración regional de la audiencia, como centro de gobierno, y de control económico y religioso en el altiplano (Borchart de Moreno 1998; Terán Najas 2000).

La fundación de una ciudad colonial española se puede caracterizar como un acto que cortó los lazos con la patria de origen, tanto para los colonos, que abandonaron su país de origen español para mudarse a un ambiente extraño, como para los nativos andinos, cuyos vínculos con los usos tradicionales de la tierra se vieron gravemente comprometidos por las nuevas relaciones coloniales. La fundación y el crecimiento de la ciudad colonial de Riobamba se puede ver como parte del crecimiento general de las relaciones capitalistas en Europa. La idea de que un momento difícil en la historia de un área puede causar un gran cambio en la relación de los pueblos con su pasado y las formas en que se conmemoran ha sido de gran interés para los arqueólogos y antropólogos (Bender y Winer 2001; González-Ruibal 2008; Wernke 2007). El movimiento de los nativos andinos desde las aldeas rurales o caseríos dispersos hacia las afueras de las ciudades coloniales es un ejemplo de estas difíciles rupturas de vínculos con los lugares tradicionales.

Las ciudades coloniales eran radicalmente nuevos lugares en el paisaje andino, con patrones de organización rectilíneos superpuestos sobre accidentes geográficos naturales, y, en muchos casos, superpuestos a los diseños precoloniales espaciales incas. Los conquistadores se hicieron cargo de grandes extensiones de territorio andino a través de la violencia e inmediatamente trataron de alterar las relaciones ideológicas tradicionales de la gente con la tierra (Hyslop 1990; Lefebvre 1991; Cummins 2002). Este urbanismo colonial impuesto es un marcado contraste con la introducción gradual de nuevas relaciones entre la tierra y la gente en la Europa moderna. Está claro que la fundación de las ciudades coloniales cambió la relación ideológica de los pueblos andinos con la tierra alrededor de ellos, y, sin embargo, las ciudades pueden ser caracterizadas como paisajes aislados y controlados de colonialismo en un espacio más amplio y mucho menos cambiante en las primeras etapas de la conquista española en los Andes.

El núcleo de cada una de estas ciudades durante el período colonial fue un diseño de cuadrícula, con manzanas alrededor de una plaza central, con vecindarios periféricos que se extienden fuera de los bordes de la cuadrícula (Rama 1984; García 1996). La ciudad colonial andina estaba dominada por el sistema de parroquias, con cada barrio ligado a una relación con la iglesia parroquial (Paniagua y Viforcos 1996; Charles 2010). En el centro de la ciudad, se ubicaba el Sagrario, que es la parroquia de la iglesia principal o catedral de la ciudad. Este núcleo de la ciudad formó el ideal de la sociedad colonial, dispuesta de manera ordenada y habitada por la élite colonial. Las parroquias periféricas poseían un papel de apoyo: proporcionaban los materiales y los productos alimenticios que mantenían el centro de la ciudad habitable. En estos contrastes entre las diferentes partes de la ciudad colonial, las nuevas relaciones políticas se formaron.

La organización urbana vinculó al gobierno municipal y al gobierno de la Iglesia en un sistema entrelazado. La Corona era el centro de poder en el sistema colonial, pero, en cada área urbana, 
Figura 2. Ubicación de Riobamba en relación a los limites de la Audiencia en los Andes del siglo XVIII (Dibujo por R. Jamieson).

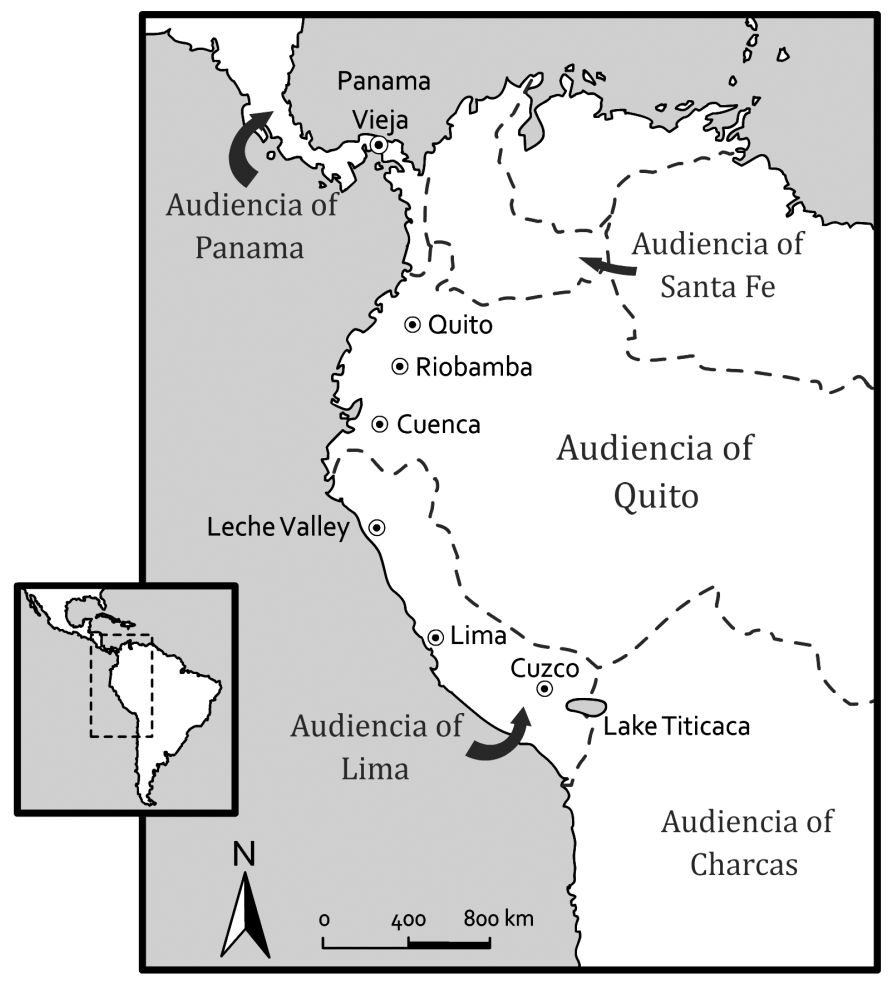

era el ayuntamiento o cabildo quien gozaba de una considerable influencia. Los cabildos urbanos regularon la vida tanto dentro de las ciudades como en los alrededores de cada centro urbano. Estos consejos estaban lejos de ser triviales y toda la Audiencia de Quito se puede representar como una red de cabildos, que controlaba cada ciudad y sus alrededores hasta las fronteras con las ciudades vecinas (Andrien 2001; Herzog, 2004).

\section{Barrio y raza}

En lugar de color de la piel o la apariencia física, fueron la ropa, la postura, el lenguaje, los antepasados de su familia, su fe religiosa profesada y — más importante- el lugar de residencia, los factores determinantes en las formas en que las autoridades coloniales clasificaron socialmente a las personas en los Andes. Estas fueron relaciones jerárquicas y, en las zonas urbanas del barrio de residencia, los vínculos con una determinada iglesia parroquial fueron factores importantes en el cálculo del origen étnico (Cope 1994; de la Cadena de 2005).

Las políticas de raza y clase fueron expresadas en la ciudad colonial andina a través de la gestión de vecindarios o barrios. Este proceso se inició con los primeros intentos coloniales por establecer ciudades en las que los nativos andinos serían estrictamente separados de los colonizadores españoles. Los colonos fueron a vivir en el centro de la ciudad; y los nativos andinos, en los vecindarios de los alrededores (Kagan 2000; Graubart 2007). Para el cabildo, esto permitiría a los indios ser sujetos más útiles del Estado facilitando la recolección del tributo y la obtención de trabajos forzados de la población urbana nativa. Por su parte, para la Iglesia, esta estricta separación en vecindarios para nativos facilitaba su evangelización. La creación de iglesias parroquiales era una forma de misiones religiosas urbanas, que atendió a las percepciones de que los andinos nativos estaban en un nivel más bajo de desarrollo espiritual y, por ende, que necesitaban un tipo diferente de proselitismo religioso que se practica en las iglesias españolas (Powers 1995; Graubart 2009). 
Como en el caso de la parroquia de San Blas en Riobamba colonial, cada barrio fue nombrado casi siempre con el mismo nombre de la iglesia parroquial. Los vínculos con esta iglesia parroquial o capilla se convirtieron en un foco importante de la vida religiosa y comunitaria en cada barrio. Los feligreses construyeron, pagaron y mantuvieron su iglesia, que normalmente se encuentra en el centro de la parroquia, en la plaza de barrio que fue el principal espacio público al aire libre, y que era también un espacio de lucha en el que las autoridades eclesiásticas y los feligreses se peleaban por la propiedad de estos edificios y la cultura material dentro de ellos. La iglesia y su contenido eran legalmente propiedad de la Iglesia católica como institución, pero los feligreses que habían creado la arquitectura y la llenaron de imágenes, tendían a verlas como de su propiedad y control. La iglesia en la plaza central de un barrio se convirtió en un símbolo cargado de pertenencia dentro de la parroquia, un simbolismo reforzado por los objetos de devoción alojados dentro que habían sido donados por los feligreses, y los cuerpos de los antepasados de los feligreses enterrados bajo y alrededor de los edificios (O'Hara 2006: 650; Gose 2008). Las parroquias individuales se convirtieron así en elementos clave en un nuevo paisaje cultural urbano, en torno al cual la vida de los feligreses fue definida.

El gobierno colonial temprano y las regulaciones de la Iglesia sobre parroquias indígenas urbanas periféricas giraban en torno a los supuestos coloniales basados en conceptos de raza, mediante los cuales agrupaban a todos los pueblos nativos andinos bajo un único y colonial término de «indio». Luego, a este mismo término era asignada la doble idea de los nativos andinos como fuente de trabajo y pago de impuestos, así como una comunidad de almas en necesidad de la conversión. En el corazón de esta dinámica, tanto en lo religioso como en el gobierno, también existía la cuestión de la pureza y la corrupción. La ciudad moderna fue vista por los colonizadores como un lugar intrínsecamente corrupto, con muchos peligros morales (Gauderman 2003; Walker 2008). Parte de los primeros esfuerzos de colonización española en la planificación de ciudades ideales era separar a los pueblos nativos de estos peligros morales, restringiéndolos a sus propias parroquias para evitar la contaminación con la corrupción de la ciudad (O’ Gorman 1938a, 1938b; O’Hara 2006).

El problema fue que esta separación en barrios racialmente segregados era imposible de mantener, debido a que el comercio, el trabajo y otras interacciones sociales borraron los límites entre las parroquias. Una pequeña minoría de los nativos andinos se hicieron bastante ricos, a menudo, debido a sus roles de liderazgo y al control de los trabajadores, y al sistema tributario en sus comunidades. Esta riqueza les permitía comprar propiedades en las parroquias centrales de la ciudad. Los matrimonios mixtos entre colonizadores y colonizados se iniciaron casi de inmediato, y pronto ciudades como Riobamba se convirtieron en lugares biológica y culturalmente híbridos, con una amplia gama de personas resultantes de la mezcla de europeos, indígenas andinos y personas de ascendencia africana. Algunos nativos andinos vendedores del mercado se movían constantemente a través de todas las parroquias de la ciudad. Los esclavos afroamericanos fueron algunas veces capaces de ganar su libertad y, a menudo, después compraban una casa en el centro de una parroquia de «nativos». Los cabildos y los distintos órdenes de la Iglesia lucharon sin descanso para crear un orden y regulación en las ciudades coloniales; sin embargo, la superposición económica, biológica y cultural, y la mezcla y la etnogénesis eran las fuerzas que no pudieron ser controladas a través de los reglamentos coloniales (Seed 1982; Cope 1994; Estrada Torres 1999). El resultado de todo esto no era un caos, sino más bien una convivencia matizada, sobre la base de diseños espaciales, relaciones humanas y políticas locales. Los barrios de Riobamba colonial alcanzaron su propia identidad al igual que los de ciudades coloniales de todo el imperio.

\section{San Blas: Una parroquia periférica de artesanos}

Nuestra excavación arqueológica en el barrio de San Blas de la ciudad colonial de Riobamba (Fig. 3) se ha traducido en la recuperación de materiales de dos contextos que datan del siglo 
XVIII (Jamieson y Sayre 2010; Balanzategui 2012). El sitio Humberto fue excavado en 2004 y consistió en una casa destruida en el terremoto de 1797, en donde el techo de teja se superpone a los pisos y los cimientos de la casa. Fueron excavados cinco metros cuadrados de arquitectura doméstica, así como - lo más importante-, al oeste de la casa, un pozo con un volumen total de cerca de 2400 litros, que contenía un número considerable de residuos domésticos que datan del siglo XVIII. Al año siguiente, se excavó otra casa, 100 metros más al sureste, llamada Lourdes debido su propietaria. Una cantidad similar de material de basural fue recuperado de este hogar.

Los apellidos de los propietarios de la parroquia en 1786 son conocidos, y eran una mezcla de nombres indígenas y españoles (Terán Najas 2000: 140). Dos manufactureras para la producción de baldosas de cerámica en esta área indican que se trataba de un centro de producción artesanal y las excavaciones de los basurales domésticos incluyen la recuperación de partes del horno con esmalte adheridos a ello, lo que indica que la producción de la cerámica mayólica se llevó a cabo en San Blas en el siglo XVIII. Sería típico de una parroquia como esta que haya sido el lugar en donde se combinaban pequeñas fábricas domésticas e industriales típicas de la producción artesanal a pequeńa escala en las ciudades coloniales andinas, que, tal vez, incluyeron la metalurgia, marroquinería, carpintería y cerámica (Paniagua y Truhan 2003).

El análisis de la cerámica de basurales de San Blas muestra una fuerte dependencia de objetos de barro simple con engobe rojo, que, por el peso de los fragmentos, representan alrededor del 90\% de los materiales de basura en el sitio Humberto, con solo el $4 \%$ del peso de fragmentos en vidriado con plomo y 6\% en vidriado mayólica (Balanzategui 2012: 43). Muchos arqueólogos suponen que el engobe rojo y los objetos simples de barro estaban siendo llevados a las casas urbanas indígenas en los Andes coloniales desde la producción local en las aldeas a las afueras de la ciudad; sin embargo, para San Blas, nuestro análisis por activación neutrónica de una pequeña muestra de tiestos indica que las mayólicas con vidriado y con engobe rojo presentes en el basural de San Blas fueron fabricados a nivel local en la zona de Riobamba y en Quito, 160 kilómetros al norte (Jamieson et al. 2012). El hecho de que ninguno de los fragmentos vino de más lejos de la región sugiere que los productos extranjeros eran casi totalmente ausentes en las mesas de siglo XVIII en San Blas. Esto demuestra que la cerámica disponible en el mercado del siglo XVIII en Riobamba fue parte de un sistema integrado en el que los minoristas adquirieron mercancías de los dos productores locales de Riobamba y Quito, ambos a la venta en el mercado de Riobamba.

Una pequeña muestra de fauna (768 fragmentos) del basural en el sitio Humberto fue analizado y evidencia una fuerte dependencia de caprinos (oveja/chivo), con menor contribución de los cerdos domésticos y el ganado (Tabla 1). Una presencia mucho menor de conejo, pato, paloma y pollo da cuenta de cierta dependencia en las pequeñas aves domesticadas, mientras que un solo hueso de un ave del pantano y un único hueso de venado sugieren cierta dependencia de menor importancia en los recursos silvestres (Tarcan 2005). La ausencia completa de cualquier fragmento de hueso identificables de camélidos o de conejillo de Indias en el conjunto es interesante, sobre todo, el conejillo de Indias, que es una especie domesticada común incluso hoy en día en la zona. La ausencia del conejillo de indias o "cuy» puede ser el resultado de un intento por retirar los elementos étnicamente indígenas de la dieta de los residentes de San Blas, pero también responder a factores tafonómicos, tales como el tamaño pequeño de los huesos y la posibilidad de que, al provenir de pequeños animales, pudieran haber sido lanzados al espacio exterior y, por ende, no acabaran con tanta frecuencia en los depósitos de basura.

El análisis de restos macrobotánicos luego de la flotación de las muestras de suelo procedentes de ambos basureros domésticos en San Blas reveló un conjunto con una cantidad significativa de quinua (Chenopodium quinoa), un pseudocereal que se adapta bien a la agricultura de altura y era común en los Andes antes de la llegada de los españoles. La muestra de la quinua es, sin embargo, abrumada por el predominio de la cebada (Hordeum vulgare) (Jamieson y Sayre 2010). Este cereal fue introducido muy temprano en la colonización española de los Andes (Cieza de León 1984 [1553]: libro I, cap. 40, 57; Garcilaso 1966 [1605]: libro IX, cap. 24, 594). Se adapta bien a gran altitud; a la escasez de precipitaciones; $y$, por ende, a la agricultura en gran parte de las tierras 


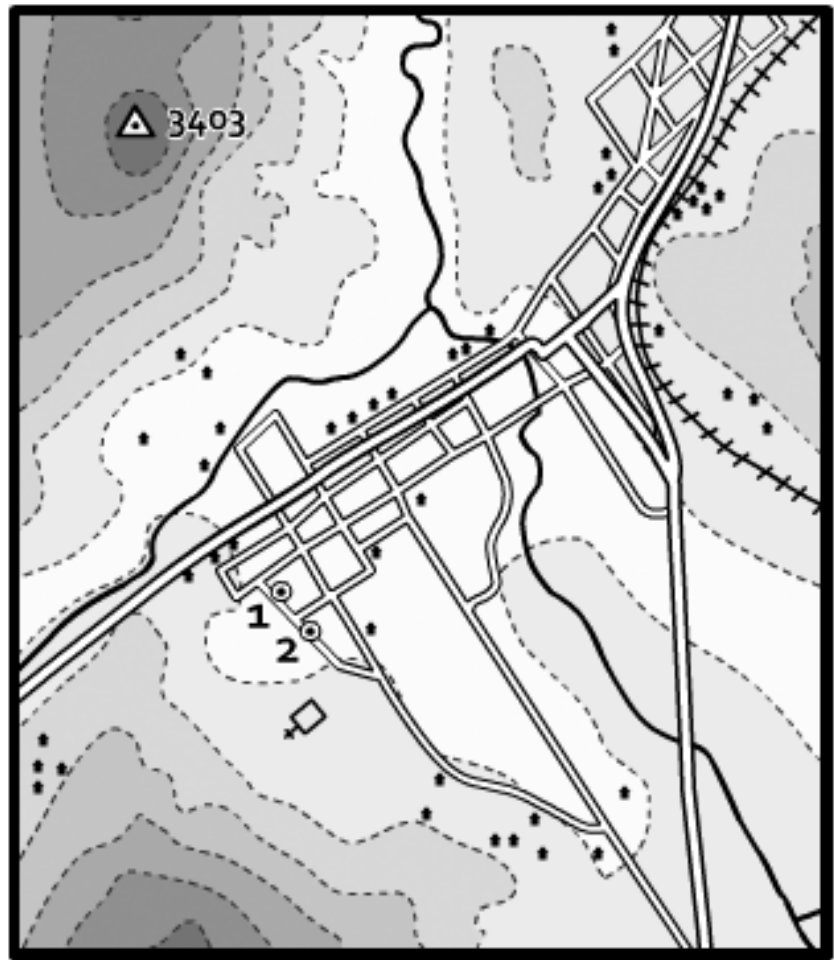

Figura 3. Sitios de excavación mencionados en el texto, en el mapa de la actual Sicalpa/Cajabamba, Ecuador. 1. Sitio Humberto. 2. Sitio Lourdes (Dibujo por R. Jamieson).

altas de Ecuador, incluidos los alrededores de Riobamba (Knapp 1991). Esta mezcla de quinua y cebada es hoy en día típica de los hogares indígenas, pobres y rurales en Ecuador, en donde estos dos granos son vistos como intercambiables en gran medida, tanto en sus aplicaciones agrícolas como en su papel en la dieta indígena andina (Weismantel 1988; Camacho 2006). El papel de la cebada en los hogares coloniales andinos parece haber sido en gran parte el mismo. Como Juan y Ulloa (1748: 398) describen, la cebada en la Audiencia de Quito fungía como alimento para los "pobres», que sirve para el pan "para los indios». La cebada y la quinua son hoy en día, y probablemente también en el período colonial, restringidos a las tradiciones alimenticias de los que vivían en la pobreza, la mayoría de los cuales eran nativos andinos.

\section{Basura doméstica, raza y barrios}

Nuestros dos basureros domésticos se encuentran no solo en el contexto colonial español, sino también en la escala local de mirar a San Blas como un barrio mayormente inclinado hacia las etnias indígenas, empleadas como artesanos, y una vida en la periferia del medioambiente urbano. El colonialismo español se basaba en la idea de «limpieza de sangre», o la pureza de sangre, un concepto vinculado con el temor de que una ascendencia judía o musulmana infecte líneas de sangre pura (de la Cadena 2005: 265). Esto dio lugar al temor de la mezcla de razas en las ciudades coloniales y, sin embargo, no se tradujo en políticas de estrictas separaciones físicas basadas en criterios raciales. La mayoría de las casas en la mayor parte de los barrios en los Andes coloniales albergaba a personas de múltiples razas, ya sean matrimonios interraciales, que vivían como propietarios, inquilinos, señores, o sirvientes o esclavos (Poloni Simard 1997). En el sistema colonial andino, el matrimonio entre razas no estaba del todo mal visto, como es el caso de los matrimonios de los conquistadores con mujeres de la nobleza inca, que unía las dos estructuras de poder para crear una clase social que fue muy superior a muchos de los españoles puros o a los nativos andinos. La raza no era realmente el problema aquí. Las categorías sociales coloniales 


\begin{tabular}{|c|c|c|c|c|}
\hline Taxa & Nombre común & Humberto NEI & Nati NEI & NEI Total \\
\hline pescados nn. & pescados no ident. & 12 & 1 & 13 \\
\hline bivalvos marinos nn. & conchas no ident. & 2 & & 2 \\
\hline Anas esp. & pato no ident. & 1 & & 1 \\
\hline Gallus esp. & gallo/pollo & 6 & & 6 \\
\hline Columba esp. & palomas & 1 & & 1 \\
\hline ave zancuda & ave zancuda no ident. & 1 & & 1 \\
\hline Aves nn. - peq. & pájaros no ident. - pequeńos & 8 & & 8 \\
\hline Aves nn. - med. & pájaros no ident. - medianos & 5 & & 5 \\
\hline Aves nn. - gra. & pájaros no ident. - grandes & 1 & & 1 \\
\hline Lagomorpha & conejo & 6 & & 6 \\
\hline Rodentia nn. & roedores pequeñas & 5 & & 6 \\
\hline Canis esp. & perro/zorro & 4 & 3 & 7 \\
\hline Felis domesticus & gato doméstico & 1 & & 1 \\
\hline carnivora - med. & carnívoros no ident. - medianos & 6 & 2 & 8 \\
\hline Odocoileus esp. & venado & 1 & & 1 \\
\hline Ovis aries & oveja & 16 & & 16 \\
\hline Capra hircus & cabra & 1 & & 1 \\
\hline Caprinae & oveja/cabra & 200 & 22 & 222 \\
\hline Sus scrofa & cerdo & 162 & 5 & 167 \\
\hline Bos Taurus & vaca & 29 & 4 & 33 \\
\hline artiodactyla - med. & artiodactyla no ident. - medianos & 157 & 26 & 183 \\
\hline artiodactyla - gra. & artiodactyla no ident. - grandes & 1 & & 1 \\
\hline ungulata - gra. & ungulados no ident. - grandes & 13 & & 13 \\
\hline Mamífero nn. - med. & mamíferos no ident. - medianos & 47 & 4 & 51 \\
\hline Mamífero nn. - peq. & mamíferos no ident. - pequeños & 3 & 1 & 4 \\
\hline Mamífero nn. - gra. & mamíferos no ident. - grandes & 8 & 2 & 10 \\
\hline Total & & $\mathbf{6 9 7}$ & 71 & 768 \\
\hline
\end{tabular}

Tabla 1. Resumen de fauna recuperada de dos basureros en el barrio San Blas.

se describen con mayor precisión como basadas en la fe ancestral, ocupación, lugar de residencia o en el vecindario de residencia (de la Cadena 2005: 265). Una idea abrumadora en las mentes de los colonizadores era el temor de que la creación inevitable de la mezcla de razas o de que las comunidades «mestizas» provocarían un conflicto social.

Los nativos andinos que habían abandonado sus territorios de origen rural, a menudo, para evitar el estatus de tributo, obtuvieron la libertad de movimiento en los barrios urbanos como San Blas. Sin embargo, las autoridades clasificaban a estas personas como peligrosas debido al cruce de las fronteras sociales, un sentimiento que parecía venir de un miedo visceral por la gente sin «raíces adecuadas» por parte de los colonizadores (de la Cadena 2005: 267). Al pasar el tiempo, y mientras los barrios urbanos de los nativos andinos y mestizos crecieron en tamaño y poder, surgió una filosofía clara por parte de muchos personajes poderosos dentro del sistema colo- 
nial: la categorización de «verdaderos» indios a quienes se quedaron en las zonas rurales, aquellos no corrompidos por la vida urbana. Los nativos urbanos andinos eran vistos como corruptos, no hispanizados como se había esperado, sino como una muchedumbre de plebeyos con todos los vicios del mundo urbano (Cope 1994; O’Hara 2006: 665). Lo que había sido un grupo racial o étnico dividido en la conquista de los Andes se había convertido en una clase social frente a los conceptos de gobernabilidad urbana de la Ilustración.

La excavación de los basurales de las casas de San Blas nos dan indicadores sobre las decisiones de los individuos y las familias. El énfasis en el consumo de fauna de la especie caprina y la cebada, ambos productos procedentes de Eurasia, evidencian que, durante el siglo XVIII, los indígenas urbanos obtuvieron muchas de sus calorías de productos europeos y, sin embargo, la principal lección probablemente se relaciona más con la gran capacidad de adaptación de las ovejas y la cebada al medio ambiente serrano. En todo caso, la falta de énfasis en el trigo y los restos de ganado podría ser visto como el más revelador de los datos, lo que contrasta la dieta de San Blas con la de los criollos ricos en el centro de la ciudad. La diferencia entre el uso de cerámica de barro rojo para mesas tanto rurales como urbanas, mientras que la fabricación de mayólicas se dirigía al mercado urbano, da cuenta de una historia de producción y consumo de bienes simbólicos que no pueden ser simplemente etiquetados a lo largo de líneas raciales. Por lo tanto, en San Blas, podemos ver lo híbrido y la naturaleza compleja de las divisiones raciales y de clase en el siglo XVIII en la ciudad colonial andina.

\section{REFERENCIAS}

Andrien, K. J.

2001 Andean worlds: Indigenous history, culture, and consciousness under Spanish rule, 1532-1825, University of New Mexico Press, Albuquerque.

Balanzátegui, D.

2012 Colonial indigenous and mestizo foodways: Ceramic analysis and ethnoarchaeology in the highlands of Ecuador, tesis de maestría, Departamento de Arqueología, Simon Fraser University, Vancouver.

Bender, B. y M. Winer (eds.)

2001 Contested landscapes: Movement, exile and place, Berg, Oxford.

Borchart de Moreno, C. R.

1998 La audiencia de Quito. Aspectos económicos y sociales (siglos XVI-XVIII), Colección Pendoneros, vol. 23, Banco Central del Ecuador/Abya Yala.

Camacho, J.

2006 Good to eat, good to think: Food, culture and biodiversity in Cotacachi, en: R. E. Rhoades (ed.), Development with identity: Community, culture, and sustainability in the Andes, 156-172, CABI Charles, J. Publishing, Cambridge. https://doi.org/10.1079/9780851999494.0156

2010 Allies at odds: The Andean church and its indigenous agents, 1583-1671, University of New Mexico Press, Albuquerque.

Cieza de León, P. d.

1984 Obras completas, vols. I, II y III, Consejo Superior de Investigaciones Científicas, Madrid.

Cope, R. D.

1994 The limits of racial domination: Plebeian society in colonial Mexico City, 1660-1720, University of Wisconsin Press, Madison.

Cummins, T. B. F.

2002 Forms of Andean colonial towns, free will, and marriage, en: C. L. Lyons and J. K. Papadopoulos (ed.), The archaeology of colonialism, 199-240, The Getty Conservation Institute, Los Angeles.

de la Cadena, $M$.

2005 Are mestizos hybrids? The conceptual politics of Andean identities, Journal of Latin American Studies 37 (2), 259-284. https://doi.org/10.1017/S0022216X05009004 
Egred, A. J.

2004 El terremoto de Riobamba del 4 de febrero de 1797, en: A. Alvarado, A. García-Aristizábal, P. Mothes y M. Segovia (eds.), Investigaciones en geociencias, vol. I, 67-86. Corporación Editora Nacional, Quito.

\section{Estrada Torres, M. I.}

1999 Fronteras imaginarias en la ciudad de México: Parcialidades indígenas y traza española en el siglo XVII, en: L. Pérez Cruz, S. Pérez Toledo y R. Elizalde Salazar (eds.), Población, espacio y cultura en México, siglos XVIII y XIX, 93-108, Universidad Autónoma Metropolitana, Iztapalapa.

Fisher, J. R., A. J. Kuethe y A. McFarlane (eds.)

1990 Reform and insurrection in Bourbon New Granada and Peru, Louisiana State University Press, Baton Rouge.

García Z., E.

1996 La ciudad en cuadricula o hispanoamericana: Origen, evolución y situación actual, Hergar, Salamanca.

Garcilaso de la Vega, E. I.

1966 Royal commentaries of the Incas and general history of Peru, University of Texas Press, Austin.

[1605]

Gauderman, K.

2003 Women's lives in colonial Quito: Gender, law, and economy in Spanish America, University of Texas Press, Austin.

González-Ruibal, A.

2008 Time to destroy: An archaeology of supermodernity, Current Anthropology 49 (2), 247-279. https://doi. org/10.1086/526099

Gose, $\mathbf{P}$.

2008 Invaders as ancestors: On the intercultural making and unmaking of Spanish colonialism in the Andes, Anthropological horizons, University of Toronto Press, Toronto.

Graubart, K. B.

2007 With our labor and sweat: indigenous women and the formation of colonial society in Peru, 1550-1700, Stanford University Press, Stanford, Calif.

2009 The creolization of the New World: Local forms of identification in urban colonial Peru, 1560-1640, Hispanic American Historical Review 89 (3), 471-499. https://doi.org/10.1215/00182168-2009-003

Herzog, T.

2004 Upholding justice: society, state, and the penal system in Quito (1650-1750), University of Michigan Press, Ann Arbor. https://doi.org/10.3998/mpub.17644

Hyslop, J.

1990 Inka settlement planning, University of Texas Press, Austin.

Jamieson, R. W.

2004 Arqueología de la antigua Riobamba: Informe preliminar, Instituto Nacional de Patrimonio Cultural del Ecuador, reporte presentado al Instituto Nacional de Patrimonio Cultural del Ecuador, Quito.

Jamieson, R. W., R. G. V. Hancock, L. A. Beckwith y A. E. Pidruczny

2012 Neutron activation analysis of Inka and colonial ceramics from central highland Ecuador, Archaeometry 55, 198-213. doi:10.1111/j.1475-4754.2012.00683.x

Jamieson, R. W. y M. B. Sayre

2010 Barley and identity in the Spanish colonial audiencia of Quito: Archaeobotany of the 18th century San Blas neighborhood in Riobamba, Journal of Anthropological Archaeology 29, 208-218. https://doi. org/10.1016/j.jaa.2010.02.003

Juan, J. y A. d. Ulloa

1748 Relación histórica del viaje a la América Meridional, Antonio Marín, Madrid.

Kagan, R. L.

2000 Urban images of the Hispanic world, 1493-1793, Yale University Press, New Haven, CT.

Knapp, G. W.

1991 Andean ecology: Adaptive dynamics in Ecuador, Dellplain Latin American Studies No. 27, Westview Press, Boulder. 
Lefebvre, $\mathrm{H}$.

1991 The production of space [traducción de D. Nicholson-Smith], Blackwell, Oxford.

Londoño, W.

2011 Arqueología histórica de Popayán y la visibilización de su cultura tradicional, Revista Colombiana de Antropologia 47 (1), 91-112.

Meskell, L.

2002 The intersections of identity and politics in archaeology, Annual Review of Anthropology 31, $279-301$. https://doi.org/10.1146/annurev.anthro.31.040402.085457

Michaels, G. C.

2009 Poverty, chastity, and obedience: Monastic masculinities in Spanish colonial Riobamba, tesis de doctorado, Departamento de Arqueología, Simon Fraser University, Vancouver.

Montes de Oca, V. P.

1983 Conquista del Perú, Quito y descubrimiento del río de las Amazonas, en: E. Ayala Mora (ed.), Nueva historia del Ecuador, vol. III, 67-90, Abya Yala, Corporación Editora Nacional, Quito.

Moreno Yáñez, S. E.

1995 Sublevaciones indigenas en la Audiencía de Quito: Desde comienzos del siglo XVIII hasta finales de la

[1976] Colonia, 4a ed., Ediciones de la Universidad Católica, Quito.

Nolasco, P.

1828 Plano topográfico del antiguo Ricpamba, o Riobamba...., Fondo Jacinto Jijón y Caamaño, Archivo Histórico, Museo del Banco Central, Quito.

O'Gorman, E.

1938a Sobre los inconvenientes de vivir los indios en el centro de la ciudad, Boletín del Archivo General de la Nación 9 (1), 1-34.

1938b Reflexiones sobre la distribución urbana colonial de la ciudad de México, Boletín del Archivo General de la Nación 9 (4), 795-800.

O'Hara, M.

2006 Stone, mortar and memory: Church construction and communities in Late Colonial Mexico City, Hispanic American Historical Review 86 (4), 647-680. https://doi.org/10.1215/00182168-2006-046

Orser, C. E.

2004 Race and practice in archaeological interpretation, University of Pennsylvania Press, Philadelphia.

Oviedo y Valdés, G. F. d.

1959 Historia general y natural de las Indias, islas, y tierra firme del mar océano, vols. I, II, III, IV, V, Biblioteca

[1535] de Autores Españoles, números 117-121, Ediciones Atlas, Madrid.

Paniagua Pérez, J. y D. L. Truhan

2003 Oficios y actividad paragremial en la Real Audiencia de Quito (1557-1730): El Corregimiento de Cuenca, Universidad de León, León.

Paniagua Pérez, J. y M. I. Viforcos Marinas

1996 El poder económico del clero secular cuencano en la segunda mitad del siglo XVII, Estudios de Historia Social y Económica de América 13, 59-77.

Parry, J. H. y R. G. Keith

1984 New Iberian World: A Documentary History of the Discovery and Settlement of Latin America to the Early 17th Century. Volume 4: The Andes, 1a ed., vols. I-V, Times Books, New York.

Poloni Simard, J.

1997 Formación, desarrollo y configuración socio-étnica de una ciudad colonial: Cuenca, siglos XVI-XVIII, Anuario de Estudios Americanos 54 (2), 413-445. https://doi.org/10.3989/aeamer.1997.v54.i2.381

Powers, K. V.

1995 The battle for bodies and souls in the colonial north Andes: Intraecclesiastical struggles and the politics of migration, Hispanic American Historical Review 75 (1), 31-56. https://doi.org/10.2307/2516781

Rama, A.

1984 La ciudad letrada, Ediciones del Norte, Hanover. 


\section{Schávelzon, D.}

2000 Historias del comer y del beber en Buenos Aires: Arqueología histórica de la vajilla de mesa, Aguilar Argentina, Buenos Aires.

Seed, P.

1982 The social dimensions of race: Mexico City, 1753, Hispanic American Historical Review 62 (4), 569-606. https://doi.org/10.2307/2514568

\section{Silliman, S. W.}

2006 Struggling with labor, working with identities, en: M. Hall y S. W. Silliman (eds.), Historical archaeology, 147-166, Blackwell, Malden.

2009 Change and continuity, practice and memory: Native American persistence in colonial New England, American Antiquity 74 (2), 211-230. https://doi.org/10.1017/S0002731600048575

St. Denis, M.

2008 El Hospital de la Real Caridad: A historical archaeology of institutional power at a Late Spanish Colonial Period hospital in the Ecuadorian Andes, tesis de doctorado, Departamento de Arqueología, Simon Fraser University, Vancouver.

Stern, S. J.

1987 Resistance, rebellion, and consciousness in the Andean peasant World, 18th to 20th centuries, University of Wisconsin Press, Madison, WI.

Tarcan, C. G.

2005 Analysis of verterbrate faunal remains from two Spanish archaeological contexts in Cuenca, Ecuador, informe no publicado en el archivo, Departamento de Arqueología, Simon Fraser University, Vancouver.

Terán Najas, R. (ed.)

2000 La antigua Riobamba: Historia oculta de una ciudad colonial, Abya Yala, Quito.

\section{Terán Najas, $R$.}

2000 La antigua Riobamba: Notas sobre el poblamiento originario y la ciudad colonial, en: R. Terán Najas (ed.), La antigua Riobamba: Historia oculta de una ciudad colonial, 15-50, Abya Yala, Quito.

Voss, B. L.

2008 Gender, race, and labor in the archaeology of the Spanish colonial Americas, Current Anthropology 49 (5), 861-893. https://doi.org/10.1086/591275

Walker, C. F.

1999 Shaking the unstable empire: The Lima, Quito and Arequipa earthquakes of 1746, 1783 and 1797, en: A. Johns (ed.), Dreadful visitations: Confronting natural catastrophe in the age of enlightenment, 113-144, Routledge, New York.

2008 Shaky colonialism: The 1746 earthquake-tsunami in Lima, Peru, and its long aftermath, Duke University Press, Durham. https://doi.org/10.1215/9780822388920

Weismantel, M. J.

1988 Food, gender, and poverty in the Ecuadorian Andes, University of Pennsylvania Press, Philadelphia.

Wernke, S. A.

2007 Analogy or erasure? Dialectics of religious transformation in the early doctrinas of the Colca Valley, Peru, International Journal of Historical Archaeology 11 (2), 152-182. https://doi.org/10.1007/s10761-007$0027-5$ 